\title{
A Corte Interamericana de Direitos Humanos e os casos de violação ao Direito Humano à Saúde
}

\author{
The Inter-American Court of Human Rights and the cases of \\ violation of Human Right to Health
}

\author{
Bruna Tassia Souza Nakayama ${ }^{1}$ \\ Ricardo Gonçalves Vaz de Oliveira ${ }^{2}$ \\ Emanuele Seicenti de Brito ${ }^{3}$ \\ Carla Aparecida Arena Ventura ${ }^{4}$
}

\begin{abstract}
Resumo: Nas Américas, há uma parcela considerável de países que apresentam um sistema de saúde excludente que separa a população entre os que podem e os que não podem ter acesso aos serviços de saúde. Quando o Estado é o violador do direito à saúde e as pessoas não possuem meios internos para buscar os seus direitos, o acesso à Corte Interamericana de Direitos Humanos (CIDH) representa importante opção, apesar de ainda desconhecida por grande parte da população no continente americano. Nesse cenário, este estudo buscou descrever os casos de violações ao direito à saúde ou de deterioração da saúde por violação a outros direitos julgados pela CIDH, observando como tem sido o esforço internacional de efetivação do reconhecimento dos direitos humanos e a condição das pessoas humanas como sujeitos de direitos e deveres nas Américas. Após a descrição e análise das sentenças inferimos que a saúde é o ponto de partida e de equilíbrio de todos os direitos sociais compondo um quadro mental e físico que torna o indivíduo o que ele é, com capacidade e competência para exercer seus direitos e cidadania. Contudo, a consolidação do direito humano à saúde como um direito e um dever dos Estados no cenário das Américas, principalmente na América Latina ainda não é efetiva, apontando um longo caminho para a construção de uma sociedade mais justa e equânime.
\end{abstract}

\footnotetext{
${ }^{1}$ Mestra em Ciências com ênfase em Direito Sanitário pelo Departamento de Enfermagem Psiquiátrica e Ciências Humanas da Escola de Enfermagem e Ribeirão Preto da Universidade de São Paulo (2016). Bacharelado em enfermagem pela EERP/USP (2013).

2 Doutorando Direto pelo Programa de Pós-Graduação em Enfermagem Psiquiátrica da Escola de Enfermagem de Ribeirão Preto da Universidade de São Paulo. Especialista em docência no ensino superior no Centro Universitário Barão de Mauá (2013). Possui graduação em Direito pelo Instituto Municipal Matonense de Ensino Superior (2012).

${ }^{3}$ Doutora (2016) e Mestra (2011) em Ciências pela Escola de Enfermagem de Ribeirão Preto da Universidade de São Paulo. Bacharela em Direito pelo Centro Universitário Toledo (2005).

${ }^{4}$ Livre Docente (2011). Doutora em Administração - Universidade de São Paulo (2004). Mestre em Direito Internacional pela Universidade Estadual Paulista Júlio de Mesquita Filho (2001). Especialista em Administração pela Universidade de São Paulo (2000). Graduada em Direito pela Universidade Estadual Paulista Júlio de Mesquita Filho (1998) e em em Relações Internacionais pela Universidade de Brasília (1993). Professora Associada do Departamento de Enfermagem Psiquiátrica e Ciências Humanas da Escola de Enfermagem de Ribeirão Preto da Universidade de São Paulo - USP.
} 


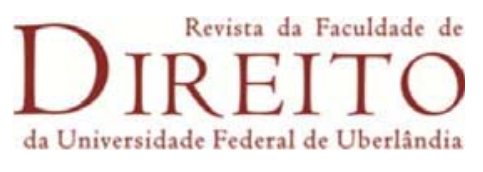

Palavras-chave: Direitos Humanos. Direito à Saúde. Violações dos Direitos Humanos.

\begin{abstract}
In the Americas there is a considerable number of countries with an excluding health system, separating the population between those who can and those who cannot have access to health services. When the State is the violator of the right to health and people do not have internal resources to pursue their rights, the access to the Inter-American Court of Human Rights (ICHR) is an important option, although still unknown by the majority of the population in the Americas. In this scenario, this study aimed to describe the cases of violations of the right to health or health deterioration due to the violation of other rights judged by the ICHR, in order to observe the international effort to put into effect the recognition of the human rights as well as the status of human beings as subjects to rights and duties in the Americas. After the description and the analysis of the sentences we consider health as the starting point and balance of all social rights, forming a mental and physical framework that makes the individual what he/she is, capable of and empowered to exercise his/her rights and citizenship. However, the consolidation of the human right to health as a right and a State duty in the scenario of the Americas, mainly in Latin America, is not effective, pointing out a long way to build a society with justice and equality.
\end{abstract}

Keywords: Human Rights. Right to Health. Violation of Human Rights.

\title{
1. Introdução
}

A história da evolução da humanidade vem sendo acompanhada por movimentos sociais que resultaram na afirmação nacional e internacional dos Direitos Humanos (DH). Como consequência deste processo, foram criados e organizados instrumentos internos no âmbito de alguns países e, posteriormente, documentos internacionais que reafirmam a necessidade de os Estados respeitarem e garantirem os direitos humanos das pessoas (ALMEIDA; APOLINÁRIO, 2009).

Dentre as iniciativas nacionais específicas destacam-se a Magna Carta da Inglaterra, em 1215, a Lei do Habeas Corpus na Inglaterra, em 1679, a Bill of Rights (Declaração de Direitos) na Inglaterra, em 1689, a Declaração da Independência dos Estados Unidos da América, em 1776, a Constituição dos Estados Unidos da América, em 1787, e a Declaração dos Direitos do Homem e do Cidadão, em 1789 na França (CURY, 2005). 
$\mathrm{O}$ movimento de proteção internacional dos $\mathrm{DH}$ consolidou-se com a criação da Organização das Nações Unidas (ONU), em 1945, com o objetivo de manter a segurança internacional e a paz estimulando o respeito universal e a liberdade sem discriminação com relação a sexo, religião, língua ou raça (BRITO; VENTURA, 2012). Em seu documento constitutivo, a ONU reconhece a dignidade inerente a todos os membros da família humana, confirmando que seus direitos são iguais e inalienáveis, como fundamento da liberdade, justiça e paz no mundo (ONU, 1945).

Logo após a sua criação e considerando o cenário de desrespeito e desprezo aos DH que levou a duas grandes guerras mundiais, em 1948, foi aprovada pela Assembleia Geral da ONU a Declaração Universal dos Direitos Humanos, adotada pela Resolução 217, que reitera a existência de direitos civis e políticos, direitos econômicos, sociais e culturais que devem ser respeitados pelos Estados. Estas dimensões foram, em 1966, consolidadas em dois tratados distintos: o Pacto da ONU sobre Direitos Civis e Políticos e o Pacto da ONU sobre Direitos Econômicos, Sociais e Culturais (ONU, 1948).

Em 1993, em Viena, durante a Conferência Mundial Sobre Direitos Humanos, essa concepção foi novamente reafirmada com a Declaração de Viena, que identificou serem os DH inter-relacionados, indivisíveis e interdependentes (PIOVESAN, 2010).

Dessa forma, consolidam-se iniciativas globais e movimentos regionais de proteção aos DH, implementados na Europa, Américas e África. O sistema europeu foi criado na década de 1950, com a Convenção Europeia sobre Direitos do Homem e a implementação da Corte e Comissão Europeia de Direitos Humanos. Atualmente, somente a Corte está em funcionamento. No contexto das Américas, em 1969, entrou em vigor a Convenção Interamericana de Direitos Humanos, criando a Corte Interamericana de Direitos Humanos (CIDH) e a Comissão Interamericana de Direitos Humanos. 
A Comissão Interamericana de Direitos Humanos, na forma do que dispõe a Convenção Interamericana de Direitos Humanos, é um órgão autônomo da Organização dos Estados Americanos (OEA), que tem como função principal promover a observância, a defesa e a promoção dos DH e servir como órgão consultivo sobre a matéria (PIOVESAN, 2010).

É composta por sete membros, cabendo-lhe receber as denúncias de violações apresentadas pelas vítimas ou por quaisquer pessoas ou organizações não governamentais contra atos violatórios de direitos fundamentais por parte dos Estados ou que não tenham encontrado reconhecimento ou proteção por parte daqueles Estados, processar essas denúncias, proceder ao seu exame e, depois de admiti-las, fazer recomendações aos Estados, e só então decidir se apresenta ou não o caso à Corte Interamericana de Direitos Humanos, que passará a decidir sobre os casos que lhe são apresentados pela Comissão ou por um estado-parte (PIOVESAN, 2010).

A Corte Interamericana de Direitos Humanos (CIDH) é composta também por sete membros com as mesmas qualificações, competindo-lhe julgar Estados por violações contra os DH em seu território. No caso das denúncias serem apresentadas à $\mathrm{CIDH}$, estas passam a ser julgadas pelos juízes que exercem competência contenciosa e consultiva, considerando a responsabilidade dos Estados por violações aos direitos ratificados pela Convenção Interamericana sobre Direitos Humanos (OEA, 1969).

A CIDH é responsável por prevenir e investigar usando todos os recursos dos quais dispuser para impedir quaisquer violações à Convenção Americana. A partir desses compromissos derivam obrigações de punir com o rigor de suas normas os que infringirem os $\mathrm{DH}$, assegurando às vítimas a reparação cabível (GUERRA,2010).

Nesse contexto, pode-se afirmar que a consolidação dos movimentos globais e regionais de proteção aos $\mathrm{DH}$ representa grande evolução na história da humanidade, uma vez que busca garantir os direitos de todas as 
pessoas. Dentre estes direitos, o direito à saúde é fundamental para assegurar a própria existência humana. Dessa forma, os DH e o direito à saúde constituem focos de discussão na atualidade como condição para a garantia do respeito à dignidade humana pelos Estados.

Outrossim, a história da humanidade revela a difícil consolidação dos direitos humanos, demonstrando em diferentes eventos transgressões e o desrespeito à pessoa humana. Como resposta, observa-se a necessidade de atuação do sistema de proteção por meio da Corte Interamericana de Direitos Humanos.

$\mathrm{O}$ direito à saúde é um direito social, previsto e protegido no plano internacional e que está sendo objeto de constantes demandas junto a organizações internacionais. No âmbito dos países americanos abrangidos pela OEA, ele se insere em uma dimensão social como consequência da evolução dos direitos fundamentais e do conceito de cidadania plena, representando um direito humano de grande importância, de caráter universal, essencial e inafastável, uma vez que se liga de forma incondicional ao direito à vida. É dotado de alto nível de normatização nos âmbitos dos direitos interno e internacional, mas não está contemplado na Convenção de 1969. Foi reconhecido quase duas décadas depois em 1988 no Protocolo de San Salvador (ORDACGY, 2008).

De acordo com o Comentário Geral 14 do Comitê da ONU sobre Direitos Econômicos, Sociais e Culturais, o direito à saúde é mais abrangente que o acesso à saúde, representando o cuidado a saúde e englobando disponibilidade, acesso, aceitação e qualidade dos serviços, além dos determinantes sociais da saúde.

Nas Américas, há uma parcela considerável de países que apresentam um sistema de saúde excludente que separa a população entre os que podem e os que não podem ter acesso aos serviços de saúde, em detrimento de renda e outros fatores. Há, portanto, um desafio disseminado por todos os territórios quando a referência é o acesso à saúde igualitário à pessoa 
humana sem quaisquer distinções (classe, gênero, etnia, escolaridade, etc.), devendo-se buscar recursos humanos e tecnológicos suficientes e que impliquem funcionamento adequado dos sistemas no âmbito de políticas públicas que garantam o direito humano à saúde, evitando uma série de violações (CONILL, 2008).

Quando o Estado é o violador do direito à saúde e as pessoas não possuem meios internos para buscar os seus direitos, o acesso à Corte Interamericana de Direitos Humanos representa importante opção. Nesse cenário, este estudo busca descrever os casos de violações ao direito à saúde ou de deterioração da saúde por violação a outros direitos julgados pela CIDH, observando como tem sido o esforço internacional de efetivação do reconhecimento dos $\mathrm{DH}$ e a condição das pessoas humanas como sujeitos de direitos e deveres nas Américas.

\section{Procedimentos do Estudo Empírico}

Trata-se de um estudo empírico-jurídico que propõe conhecer e analisar decisões da CIDH relacionadas à violação do direito humano à saúde no contexto das américas. Para tanto, o desenho metodológico empregado fundamentou-se na pesquisa documental, a qual se caracteriza pela busca de informações em documentos que não receberam nenhum tratamento científico, ou seja, diretamente nas fontes primárias (SA-SILVA; ALMEIDA; GUIDANI, 2009).

Para encontrar tais documentos, foi realizada no buscador de jurisprudências utilizando a palavra-chave "salud", no sítio da CDHI. A palavra chave foi utilizada em espanhol por tratar-se da língua oficial utilizada naquele ambiente e nos documentos analisados.

De um total de vinte e três casos encontrados, foram selecionados os que indicavam relação direta com a violação de direitos à saúde. Foram excluídos os casos nos quais a palavra saúde direcionou a decisões de casos 
não diretamente relacionados ao contexto da saúde, tais como episódios de tortura e violência.

O conteúdo da jurisprudência encontrada foi exaustivamente lido, sendo extraídos e analisados e discutidos com subsídio da literatura sobre o objeto de estudo. Como resultados, foram encontradas duas decisões que se relacionavam diretamente com o objeto proposto: o Caso Ximenes Lopes do Brasil (CIDH, 2006) e o caso Albán Cornejo do Equador (CIDH, 2007).

\section{Introduction Caso Damião Ximenes Lopes contra o Estado da República Federativa do Brasil}

Em meados de outubro de 1999, Damião Ximenes Lopes, portador de transtorno mental, faleceu pelas supostas condições desumanas e degradantes da sua hospitalização e pelos alegados golpes e ataques contra a integridade pessoal por parte dos funcionários da Casa de Repouso Guararapes, localizada no estado do Ceará, Brasil.

Damião se encontrava amarrado, munido de hematomas e escoriações por todo o corpo ao falecer, segundo o laudo, em função de parada cardiorrespiratória por causa desconhecida, fato que resultou na desestruturação familiar e levou à mãe da vítima a um forte quadro de depressão. Esse cenário levou a irmã da vítima, Irene Ximenes Lopes, a buscar justiça que, uma vez não encontrada em seu Estado, resultou na procura pela Comissão Interamericana. O caso foi submetido à Comissão Interamericana de Direitos Humanos em 22 de novembro de 1999 e submetido à CIDH em primeiro de outubro de 2004.

A CIDH considera que o Estado não executou a justiça, e estabeleceu que, transcorridos mais de seis anos dos fatos, os autores dos tratamentos cruéis, desumanos e degradantes, bem como da morte do senhor Damião Ximenes Lopes, não foram responsabilizados, prevalecendo a impunidade. A CIDH concluiu que houve violação do direito à vida, à garantias judiciais e 
proteção judicial e reconheceu a responsabilidade internacional estatal de regulamentar e fiscalizar toda a assistência de saúde prestada às pessoas sob sua tutela.

$\mathrm{O}$ conhecimento da verdade dos fatos em violações de $\mathrm{DH}$ é um direito inalienável e um meio importante de reparação para a suposta vítima e, quando cabível, para seus familiares, além de constituir uma forma de esclarecimento fundamental para que a sociedade possa desenvolver mecanismos próprios de desaprovação e prevenção de violações como essas no futuro. Como consequência, os familiares das vítimas têm o direito e os Estados têm a correspondente obrigação a que o ocorrido seja efetivamente investigado pelas autoridades estatais, a que se inicie um processo contra os supostos responsáveis por esses ilícitos e, se for o caso, de que lhes sejam impostas as sanções pertinentes.

O Estado não cumpriu as suas obrigações para com inquéritos, processos, captura, julgamento e punição dos responsáveis pela morte da vítima. De acordo com a Corte, o Estado ignorou completamente a prova, deixando as vítimas totalmente desprotegidas judicialmente e possibilitando a impunidade dos responsáveis pela morte de Damião.

Ao final do julgamento, a $\mathrm{CIDH}$ reconheceu a responsabilidade do Estado em garantir, em prazo razoável, que o processo interno destinado a investigar e sancionar os responsáveis pelos fatos deste caso surtisse seus devidos efeitos.

Em razão dessa decisão, coube ao Estado indenizar a vítima e continuar a desenvolver um programa de formação e capacitação para o pessoal médico, de psiquiatria e psicologia, de enfermagem e auxiliares de enfermagem e para todas as pessoas vinculadas ao atendimento de saúde mental, em especial sobre os princípios que devem reger o trato das pessoas portadoras de deficiência mental, conforme os padrões internacionais sobre a matéria e aqueles dispostos na sentença. 


\section{Caso Albán Cornejo contra o Estado do Equador}

Em 18 de dezembro de 1987, Laura Albán Cornejo faleceu pela suposta aplicação de 10 miligramas de morfina prescritos por um médico residente durante a internação em um hospital privado de Quito, Equador, por meningite. $\mathrm{O}$ caso foi submetido à Comissão Interamericana de Direitos Humanos em 31 de maio de 2001 - sem qualquer tipo de resolução amigável e, então, submetido à CIDH em 05 de julho 2006. Os genitores da vítima buscaram, sem sucesso, uma resposta do Estado para que apurasse o homicídio que acreditavam ter ocorrido. Este fato resultou na fragilização familiar e levou os pais da vítima a partirem em busca de justiça que, ao não ser encontrada internamente, foi reconhecida em âmbito internacional por meio da CIDH.

A CIDH considerou que o Estado não executou a justiça, transferindo esta tarefa para os pais de Laura, fracassando em sua função de inspecionar e avaliar periodicamente os estabelecimentos de saúde, públicos ou privados, assim como no seu dever de avaliar o conhecimento e a capacidade da profissão médica.

$\mathrm{A} \mathrm{CIDH}$ concluiu que houve violação do direito à integridade pessoal, às garantias judiciais, à liberdade de pensamento e de expressão e à proteção judicial, além de violação do direito à proteção da família estabelecidos na Convenção Americana de Direitos Humanos.

A Corte também afirmou que o Estado não garantiu o direito à vida por causa da falta de legislação específica em caso de negligência médica, falta de meios de proteger efetivamente a lei e má aplicação da justiça. Considerou que o Estado é responsável por ter falhado em seu dever de prevenir quaisquer violações a $\mathrm{DH}$ que possam surgir.

O Estado não cumpriu as suas obrigações relacionadas a inquéritos, processos, captura, julgamento e punição dos responsáveis a morte da vítima e ignorou completamente a prova, deixando as vítimas totalmente 
desprotegidas judicialmente e possibilitando a impunidade dos responsáveis pela morte de Laura.

Ao final do julgamento, o Tribunal reconheceu o dever do estado de promover ações para garantia do direito à saúde, afirmando que o Estado deve ter uma legislação eficaz para assegurar aos usuários do serviço de saúde atendimento eficaz. A Corte intimou o Estado a rever a legislação penal em caso de negligência médica e adaptar o sistema de saúde para que este promova uma conduta adequada. A CIDH incumbiu ao Estado a adoção de medidas para acompanhar e fiscalizar a prestação serviços de saúde e a garantia do direito à vida, à integridade pessoal e saúde para as pessoas que estão sob tratamento médico.

Ao Estado foi imputado de realizar, dentro de um prazo razoável, a ampla divulgação dos direitos dos pacientes, utilizando os meios de comunicação. Ainda, o Estado foi obrigado a indenizar a família da vítima e ficou comprometido enquanto dever estabelecido de fomentar, dentro de um prazo razoável, um programa de treinamento e formação de oficiais de justiça e profissionais de saúde sobre as regras do Equador, em relação aos direitos dos pacientes, e a pena para o seu padrão nos termos devidos da sentença.

\section{Síntese das fundamentações jurídicas utilizadas nas decisões da $\mathrm{CIDH}$}

As fundamentações jurídicas das decisões foram organizadas em quadro próprio, para maior compreensão do tema discutido.

Quadro 1 - Fundamentação jurídica referente a cada sentença analisada

\begin{tabular}{|l|l|}
\hline Caso Damião Ximenes Lopes & $\begin{array}{l}\text { Violação dos artigos: } 4^{\circ} \text { (Direito à Vida); } 5^{\circ} \text { (Direito à } \\
\text { integridade pessoal); } 8^{\circ} \text { (Direito às garantias judiciais); } \\
25 \quad \text { (Direito à proteção judicial) da Convenção } \\
\text { Americana de Direitos Humanos. }\end{array}$ \\
\hline
\end{tabular}




\begin{tabular}{|l|l|}
\hline Caso Albán Carnejo & $\begin{array}{l}\text { Violação dos artigos: } 4^{\circ} \text { (Direito à Vida); } 5^{\circ} \text { (Direito à } \\
\text { integridade pessoal); } 8^{\circ} \text { (Direito a garantias judiciais); } \\
13 \text { (Direito à liberdade de pensamento e de expressão); } \\
17 \text { (Direito à proteção da família); } 25 \text { (Direito à proteção } \\
\text { judicial) da Convenção Americana de Direitos } \\
\text { Humanos. }\end{array}$ \\
\hline
\end{tabular}

Fonte: elaboração própria.

\section{Discussão}

Conforme postulado por Zelada (2007), quando se produz uma ruptura forçada por fatores externos à vontade humana que destroem seu projeto de vida de maneira injusta e arbitrária, o direito não pode calar-se e mesmo com relação a fatos cujos danos morais parecem irreparáveis, deve se buscar, de alguma forma, atenuá-los.

Nos casos analisados, foi possível verificar que a Corte representou importante mediador para que vítimas buscassem a reparação de seus direitos por parte do Estado violador, permitindo que suas vozes fossem ouvidas. Dessa forma, a fundamentação jurídica das decisões analisadas expõe a fragilidade da garantia dos $\mathrm{DH}$ e do cumprimento da proteção judicial da pessoa humana dentro do ordenamento jurídico dos países envolvidos, incluindo neste o Brasil.

Nas situações analisadas, verificou-se a importância do reconhecimento do ius postulandi da vítima, ou de seus respectivos representantes em casos de sucessões processuais, para postularem perante o organismo internacional da Comissão Interamericana denunciais de violações de $\mathrm{DH}$, a qual, acabou por reencaminhar os casos para análise da Corte, sendo exigido tão somente a relação entre o reclamante e o dano ou violação dos Direitos Humanos que este denuncia, o que também é apontado e destacado nos estudos elaborados por Fonseca (2010).

As violações das proteções previstas na Convenção Americana Sobre Direitos Humanos, especialmente ao direito à vida (artigo $4^{\circ}$ ), direito à 
integridade pessoal (artigo $5^{\circ}$ ), direito à liberdade de pensamento e de expressão (artigo 13) e direito à proteção da família (artigo 17) são marcantes em razão de sua relação direta com o direito à saúde, uma vez que a saúde encontra-se entre os bens intangíveis e mais inestimáveis do ser humano. Neste contexto, como destacado por Ordacgy (2008), este bem é digno de receber a tutela protetiva do Estado, pois é indissociável do direito à vida e de proteção do indivíduo enquanto corpo, cidadão, membro de uma família e de uma sociedade.

No tocante as violações do direito à vida (artigo $4^{\circ}$ ) praticadas pelos estados, representa ferir o princípio e fundamento ético político do conjunto de todas as ações humanas e dissociar o fundamental princípio de dignidade. Sem a presença, para além do físico e do biológico, de seres humanos não há porque declarar a defesa de seus $\mathrm{DH}$. O direito à vida comtempla a segurança social, a habitação, condições de alimentação e sobrevivência com dignidade e a integridade pessoal. Para a defesa intransigente da vida é dever de todos os Estados a sua promoção e qualificação, diretamente ligada a garantia do direito à saúde (ANDRADE, 2008).

Já nos casos de violação ao o direito à integridade pessoal (artigo $5^{\circ}$ ), a agressão instaura no ser humano marcas que transcendem o físico e que, no caso de negligência e passividade estatal, tornam o cidadão vítima de seu protetor.

Quanto ao direito à liberdade previsto no artigo 13, aponta-se que a repressão e forte influência política ensejam no atentado contra a liberdade de expressão e ferem o direito a ela, influenciando, também, a saúde do homem, seguindo a mesma linha de proteção já prevista na Declaração Universal dos Direitos do Homem preceitua, no artigo III, a qual preceitua que o homem tem direito à vida, à liberdade e à segurança pessoal. Sendo assim, o direito à saúde representa um direito humano fundamental ligado intimamente à liberdade por possuir relação indissociável com o direito à vida (ORDACGY, 2008). 
O desafio da melhoria efetiva na saúde apresenta-se com alto grau de complexidade e grande relevância política por envolver gestões governamentais amplas e intersetoriais que exigem determinação e investimento de médio a longo prazo (WRIGHT, 2008).

$\mathrm{Na}$ América Latina, problemas graves envolvem o cumprimento dos direitos humanos enquanto política internacional, apesar de cada vez mais países cumprirem as proibições contra tortura, desaparecimentos e terem aumentado o número de normas regionais relativas aos DH. Contudo a América Latina ainda detém resquícios do comportamento governamental de regimes ditatoriais que prevaleceram até meados da década de 1970 (LUTZ; SIKKINK, 2000).

Investir em DH significa investir amplamente na articulação dos setores sociais para atingir toda a população por meio da atenuação das disparidades e este representa um desafio gerencial, especialmente na América Latina onde a desigualdade social é tão antiga quanto a própria história da região.

A situação de vulnerabilidade aliada às turbulentas condições socioeconômicas de muitos países latino-americanos agrava diretamente os processos de integração social e, em algumas situações, fomenta o aumento da violência e da criminalidade. Isso torna o ser humano vulnerável e mais vulneráveis as minorias como as pessoas que possuem transtorno mental, indígenas e mulheres, cujos direitos foram reconhecidos como violados pela Corte Interamericana de Direitos Humanos nas sentenças analisadas neste estudo.

A dignidade humana será sintetizada apenas se houver a implementação de um tratamento igualitário destinado a todos os indivíduos, independente de raça, cor, credo, condição social, estado e finalmente sexo e capacidade mental. Esta é a única maneira de garantir um "mínimo existencial" para todo cidadão. Contudo não é possível se 
atingir a igualdade quando se confere a todas as pessoas direitos formais matemáticos e idênticos.

A igualdade social só é efetivamente conquistada quando respeitadas as diferenças dos indivíduos, sejam estas sociais, econômicas e mentais e quando estas são amparadas de forma plena pelo Estado e por toda a sociedade a fim de proporcionar a superação das dificuldades existentes e a participação ativa deste indivíduo na vida comunitária e social em geral (MEDEIROS, 2004).

As decisões analisadas apresentavam como vítimas grupos vulneráveis da população, uma criança (caso Albán Cornejo) e uma pessoa com transtornos mentais (caso Ximenes Lopes). Estes grupos se encontram na linha de frente da exposição da violação dos direitos por serem carecedores de máxima proteção de seus direitos. Estas situações estão dir eta ou indiretamente ligadas ao exercício do direito à saúde, considerado em sua conceituação mais abrangente, pois possibilitam o gozo de outros direitos, ligados à vida, liberdade e integridade física e mental.

Porto (2007), ao conceitual a vulnerabilidade, a descreve como dinâmica, polissêmica, transdisciplinar, de múltiplas dimensões qualitativas e que está associada não apenas ao quesito da fragilidade ou condição, mas também à desvantagem social em que vive seus atores (PORTO, 2007). Nesta linha de pensamento, o acesso a saúde conforme desenhado nas normas internacionais de direitos humanos, engloba a proteção, promoção e recuperação de indivíduos que devem ter suas especificidades reconhecidas e respeitadas (SCHWARTZ, 2001)

É nesse leque de proteção que caminha o atual desafio para a CIDH no continente latino americano, ou seja, definir e estabelecer mecanismos que assegurem a viabilidade dos $\mathrm{DH}$ no direito interno estatal e de sua doutrina, trabalho que deve estar acompanhado da vontade real e efetiva dos Estados para avançar em um modelo de proteção apesar de suas imperfeições. Pois, apesar de diversas dificuldades, é possível afirmar que a 
CIDH desempenha um importante papel ao ser o último instrumento para o amparo das vítimas das mais graves ocorridas no continente (ZELADA, 2007).

\section{Conclusão}

As diferenças narradas nos casos expõem a dificuldade de proteção ao direito à saúde previsto em normas internacionais, especialmente na Convenção Americana de Direitos Humanos. Os Estados carregam consigo uma capacidade ambivalente e tênue entre proteger e violar o direito do cidadão pelo simples ato de se abster de seu papel primordial: o de proteção do cidadão.

Nota-se que a CIDH vem usando de dinamismo, criatividade e audácia, reconhecendo os direitos destes grupos e incluindo em seus julgados reparações monetárias e não monetárias para as vítimas. A CIDH internaliza estes valores e busca que os países incorporem em seus ordenamentos jurídicos esta proteção, assim como desenvolvam políticas públicas que garantam internamente o respeito à diversidade. Contudo, a combinação de diferentes vulnerabilidades observada nos casos analisados fragiliza a garantia dos direitos pelos Estados, que assumem que os recursos à sua disposição ainda são insuficientes para sua superação ou para evitar a violação de $\mathrm{DH}$ por meio de violência física e moral.

Propõe-se, portanto, o fortalecimento do capital social por meio do aumento da participação e valorização das formas de organização humanas, como estratégia de ação para envolver a sociedade e seus recursos na busca de soluções conjuntas para os problemas de vulnerabilidade. Diminuir a vulnerabilidade por meio do fortalecimento da sociedade é a base da melhoria para um percurso real de efetivação da garantia de direitos pelos Estados.

Os regimes democráticos devem ser sensíveis à aceitação das diferenças, promovendo igualdade e respeitando a dignidade dos seres 


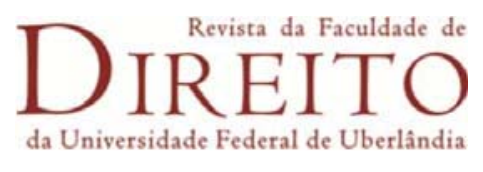

humanos, potencializando possibilidades e alternativas de todos os indivíduos, especialmente os mais vulneráveis como mulheres, crianças, grupos indígenas e pessoas com transtornos mentais.

Há um longo caminho pela frente para que seja consolidado um modelo humanizado de cuidado à saúde particularmente na América Latina. Os documentos analisados demonstram que os membros da OEA encontram dificuldades na proteção dos DH relacionados a saúde. Por isso, garantir a proteção dos DH é um desafio, um horizonte vislumbrado que depende dos Estados e das pessoas que o compõem em todas as suas esferas de formação. Sejam as pessoas, governantes ou governados, existe a necessidade de ação conjunta e voz ativa para a concretização da justiça e da igualdade.

Neste sentido, garantir os DH seria o próprio caminho de construção de uma sociedade socialmente mais equânime, com fundamento com fundamento na cidadania, sendo a saúde um dos principais pontos de partida e de equilíbrio de todos os direitos sociais, uma vez que compõe um quadro mental e físico que torna o indivíduo o que ele é, com capacidade e competência para exercer seus direitos e cidadania.

\section{Referências}

ALMEIDA, G.A.; APOLINÁRIO, S.M.O.S. Direitos Humanos. São Paulo: Atlas, 2009.

BARDIN, L. Análise de Conteúdo. Rio de Janeiro: Edições 70, 1995.

BICUDO, H. Defesa dos direitos humanos: sistemas regionais. São Paulo,2003. Disponível em: http://www.scielo.br/scielo.php?pid=S0103-40142003000100014\&script=sc i_arttext. Acessado em 12 abr. 2017.

CONILL, E.M. Sistemas comparados de Saúde. In: Saúde Mental e Saúde Coletiva. In: Conill, E.M. Sistemas comparados de Saúde. In: CAMPOS, G. W. S.; MINAYO, M.C. S.; AKERMAN, M.; DRUMOND JÚNIOR, M.; CARVALHO, Y. M. (organizadores). Tratado de saúde coletiva. Rio de Janeiro, Hucitec; Fiocruz, 2006. Pp. 563-613.

CIDH. Corte Interamericana de Direitos Humanos. Caso Ximenes Lopes vs. Brasil. Fondo, Reparciones y Costas, 2006.

CIDH. Corte Interamericana de Direitos Humanos. Caso Albán Cornejo y otros. vs. Ecuador. Fondo Reparaciones y Costas, 2007.

CURY, I.T. Direito Fundamental à Saúde. Rio de Janeiro: Lumen Juris, 2005.

FONSECA, E.F. Notas e reflexões sobre a jurisprudência internacional em matéria ambiental: a participação de indivíduos e organizações não governamentais. Ambiente \& Sociedade, v.8, n. 2, pp. 243-259, 2010. 


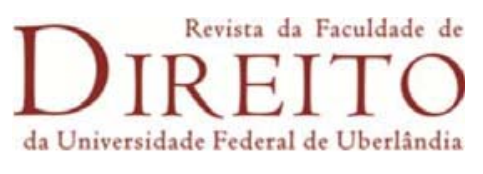

GIL, A.C. Métodos e Técnicas de Pesquisa Social. São Paulo: Atlas, 2008.

GUERRA, S. O Sistema Americano de Proteção aos Direitos Humanos: Uma breve análise sobre o caso Damião Ximenes Lopes. Unigranrio.Rio de Janeiro 2010.

LUTZ, E.L.; SIKKINK, K. International Human Rights Law and Practice in Latin America. International Organization, v. 54, n. 3. p. 633-660, 2000.

MEDEIROS, C.C.S. Saúde Mental e Direito: ensaios em homenagem ao professor Heitor Carrilho. São Paulo: Método, 2004.

MERCY, J.A; Rosenberg, M.L.; POWEL, K.E.; BROOME, C.V.; ROPER,W.L. Public health policy for preventing violence. Health Affairs, v. 12, n.4, pp. 7-29, 1993.

OEA. (Organização dos Estados Americanos). Convenção Americana Sobre Direitos Humanos. San José: OEA, 1969.

ORDACGY, A.S. O Direito Humano Fundamental à Saúde Pública. Rio de Janeiro: Federação Brasileira de Hospitais, 2008.

ONU. (Organização das Nações Unidas). Carta das Nações Unidas. Nova Iorque: ONU, 1945.

ONU. (Organização das Nações Unidas). Declaração Universal dos Direitos Humanos. Nova Iorque: ONU, 1948.

Nações Unidas no Brasil. OMS e UNICEF firmam parceria para melhorar saúde na América Latina e Caribe. Nações Unidas no Brasil, Brasília, 27 junho 2013. Disponível em: $\quad<$ http://www.onu.org.br/oms-e-unicef-firmam-parceria-para-melhorar-saude-naamerica-latina-e-caribe/ >. Acesso em: 13 set. 2017.

PIOVESAN, F. Direitos Humanos e o Direito Constitucional Internacional. São Paulo: LTR, 2010.

PIOVESAN, F. Democracia, Direitos Humanos e Globalização Econômica: desafios e perspectivas para construção da cidadania no Brasil. Disponível em: $<$ http://www.idec.org.br/publica/500anos/flavia.htm>. Acesso em: 14 abr. 2017. conferir

PORTO, M.F.S. Uma ecologia política dos riscos: princípios para integrarmos o local e o global na promoção da saúde e da justiça ambiental. Rio de Janeiro: Fiocruz, 2007.

SÁ-SILVA, J.R.; ALMEIDA, C.D.; GUIDANI, J.F. Pesquisa documental: pistas teóricas e metodológicas. Revista Brasileira de História \& Ciências Sociais. a. 1, n. 1, pp. 1-15, 2009.

SCHWARTZ, G. Direito à saúde: efetivação em uma perspectiva sistêmica.Porto Alegre: Livraria do advogado, 2001.

WRIGHT, J.T.C. A Saúde no Brasil e na América Latina. São Paulo: Fundação Instituto de Administração, 2008.

ZELADA, L.G. Proteción de La Víctima, cuatro critérios de la Corte Interamericana de Derechos Humanos: interpretación evolutiva. Ampliación del concepto de víctima, dano al projecto de vida y reparaciones. Revista chilena del derecho, v. 34, n. 3, pp. 439-455, 2007. 